\title{
Entre a educação e a ciência: um percurso acadêmico-institucional*
}

Fernanda A. da F. Sobral**

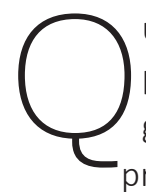
uando recebi o convite dos meus colegas do Departamento de Sociologia para proferir uma aula inaugural sobre meu percurso acadêmico, não imaginei que esse ato de rememorar me proporcionasse tantos momentos de prazer e de emoção, com as lembranças suscitadas. Inicialmente, fiquei na dúvida sobre qual seria o eixo ou o foco dessa aula. Porém, quando colegas que trabalham na área de estudos sociais em ciência e tecnologia (C\&T) me pediram para eu apresentar, num seminário internacional, uma retrospectiva desses estudos no nosso departamento, pude perceber, ao analisar a nossa produção, que tanto a linha de pesquisa que atualmente se chama Educação, ciência e tecnologia, como a minha própria trajetória tinham sido feitas por meio de uma associação entre a sociologia da educação e a sociologia da ciência. Encontrei então o eixo de minha aula. Por essa razão, a intitulei "Entre a educação e a ciência: um percurso acadêmico-institucional". Também ficou claro que minha carreira acadêmica foi construída ao mesmo tempo em que ajudei a construir, junto com muitos colegas, uma instituição, que foi esse departamento, o programa de pós-graduação em sociologia da UnB e a nossa linha de pesquisa. E essa instituição muito me ofereceu tanto no que concerne à minha formação, como ao desempenho na minha carreira acadêmica. Ou seja, a construção foi recíproca. A relação entre indivíduo e sociedade, permeada pelas instituições, sempre me apaixonou e foi objeto de alguns cursos que dei nesse longo caminho. Mas quero ressaltar que essa construção institucional é uma obra coletiva e hoje consolidada.

O casamento entre educação e conhecimento vem de longa data. Minha dissertação de mestrado, foi orientada pela professora Barbara Freitag, defendida em 1976, intitulada "Educação e mudança social: uma tentativa de crítica", depois seria publicada como livro. Ainda que o título tenda a categorizá-la exclusivamente como estudo sobre educação, de fato trata da produção de conhecimento sobre o papel da educação no processo de transformação das sociedades. Numa perspectiva estruturalista e marxista, mostrei a influência do contexto histórico na produção sobre educação, procurando apontar os aspectos ideológicos presentes em duas categorias de estudos: nos estudos sobre mobilidade educacional, muito em voga a partir da década de 1950, quando, após a Segunda Guerra Mundial, se queria legitimar
* Aula inaugural proferida em 27 de abril de 2016. ** Professora/
pesquisadora sênior
do Programa de
Pós- graduação em
Sociologia (UnB).
Tem doutorado em
sociologia na UnB
e realizou pós-
doutoramento em
Paris, na École das
Hautes Études em
Sciences Sociales,
entre 1989 e 1990.
<fernanda@unb.br>. 
a social democracia ameaçada pela ideologia fascista do passado e pelo socialismo soviético; e nos estudos sobre aspectos econômicos da educação, a partir da década de 1970, quando se pretendia legitimar o crescimento econômico e tecnológico nos moldes da sociedade capitalista desenvolvida. Esse momento foi marcado pelo crescimento econômico surpreendente da Alemanha e do Japão do pós-guerra, fenômeno impossível de ser explicado pelos três fatores clássicos (terra, capital e trabalho), sendo necessária a utilização do conceito de capital humano.

Dando continuidade a essas ideias, em 2001 escrevi o artigo "Educação para a competitividade ou para a cidadania social?", no qual apresentei as concepções de educação como promotora da competitividade e da cidadania social, vigentes a partir da década de 1990, mostrando como essas concepções se refletiam na política educacional brasileira por estarem relacionadas a certas transformações da sociedade, nas quais se incluem o processo de globalização e a consolidação da democracia.

Comecei a dar aula na UnB em 1975, há 40 anos, enquanto auxiliar de ensino e ainda aluna de mestrado. Nessa época, éramos contratados para dar aulas de Introdução à sociologia, mas, em 1976, recém-mestra, fui encarregada de dar uma disciplina de Sociologia da educação, na qual tive o prazer de ter como alunas as professoras Maria Stela Porto e Mariza Veloso e o desafio de ter na minha sala alunos das mais variadas tendências políticas e ideológicas. Aprendi a ouvir e a refletir com o embate de posições, mas também a sobreviver diante deles. Ou seja, minha primeira disciplina específica foi Sociologia da educação, temática relacionada à minha dissertação. Depois de algum tempo de meu contrato como auxiliar de ensino, fui chamada para voltar ao Departamento de Ciências Sociais, como professora colaboradora, pela então chefe, professora Safira Amann, do Serviço Social, tendo apenas me tornado professora efetiva em 1978, depois de muitas lutas coletivas para acabar com essa categoria temporária de professor. Desde então, lecionei inúmeras vezes Teorias sociológicas, sobretudo clássicas, Sociologia da educação, Sociologia da ciência e tecnologia e Prática de ensino em ciências sociais, além da tradicional Introdução à sociologia.

Em 1984 entrei para o doutorado, ou seja, fui da primeira turma do doutorado e a minha tese foi a primeira defendida nessa linha de pesquisa, ainda que, em 1975, Regina Morel tenha concluído a primeira dissertação de mestrado intitulada "Considerações sobre a política científica no Brasil", que depois se tornou livro e referência para a nossa área. Se, anteriormente, eu já apresentava um interesse implícito pela produção de conhecimento, esse se tornou mais claro durante o doutorado, quando procurei analisar as condições de produção de conhecimento ou da pesquisa nas universidades e em outras instituições de pesquisa. Por essa razão, minha tese, de- 
fendida em 1988 e orientada pela professora Vilma Figueiredo, se intitulou: "Ciência, tecnologia e poder: os interesses sociais na pesquisa", que tratou da produção e apropriação social da pesquisa biomédica na Universidade Federal do Rio de Janeiro (UFRJ) e na Fundação Oswaldo Cruz (Fiocruz) e da pesquisa agronômica na UnB, na Universidade Federal Rural do Rio de Janeiro (UFRRJ) e na Empresa Brasileira de Pesquisa Agropecuária (Embrapa), procurando verificar os determinantes sociais (de ordem econômica, política e ideológica) das atividades de pesquisa, observando os interesses sociais em jogo, tanto na produção como na apropriação da pesquisa, e indicando os principais beneficiados com os resultados das pesquisas, bem como os fatores intervenientes para que determinados resultados não fossem utilizados ou mesmo divulgados.

Neste sentido, trabalhei com as ideias de C\&T como força produtiva, baseada em Marx, de ciência e tecnologia como dominação política a partir de Marcuse e de ciência e tecnologia como ideologia, segundo Habermas. Como o contexto maior analisado era do capitalismo dependente, constatei que, embora a interação com o setor produtivo não fosse uma forte tendência na época, a C\&T, nas áreas por mim analisadas e sobretudo nas instituições estatais de pesquisa, podia ser considerada embrionária e indiretamente como forças produtivas. Ou seja, estavam reforçando a própria situação de dependência por meio da importação de produtos ou da simples adaptação de descobertas realizadas no exterior ou mesmo de produções próprias que atendiam interesses de acumulação do capital internacional. Nas universidades, nas quais se desenvolvia principalmente a pesquisa básica, havia um maior grau de autonomia. Ao mesmo tempo, a C\&T também podia ser considerada como dominação política, na medida em que o Estado brasileiro procurava legitimar-se pela política e pela produção científica e tecnológica. Era o caso da produção de vacinas e de medicamentos que podem beneficiar toda a sociedade. No que concerne à visão da C\&T como ideologia, foi observada uma tentativa de ofuscar uma realidade social desigual e dependente. A pesquisa agrícola da Embrapa, de grande importância nacional e internacional, por exemplo, era motivada, naquele período, principalmente pelo aumento de produtividade da agricultura, sabendo-se que muitas dessas tecnologias agrícolas produzidas não podiam ser apropriadas pelos pequenos produtores rurais, por falta de condições infraestruturais. A questão da estrutura fundiária era substituída pela modernização da agricultura (por meio das novas tecnologias), observando-se a dimensão ideológica da C\&T.

Num período em que a neutralidade da ciência era quase um dogma, recebi críticas da banca examinadora que reforçou principalmente a autonomia da pesquisa e a importância da própria evolução da ciência no processo de produção de conhecimento, que não deixava de estar presente na minha tese, mas que não foi 
destacada em sua devida importância, na medida em que eu estava preocupada, à luz do arcabouço teórico escolhido, em mostrar os determinantes sociais da pesquisa científica e tecnológica. Com o tempo, fui evoluindo no sentido de analisar as condições cognitivas e socioinstitucionais da produção do conhecimento e não apenas os determinantes sociais. Referente aos resultados da minha tese, publiquei três artigos: "Os entraves burocrático-políticos à pesquisa cientifica e tecnológica", "A produção e a apropriação social da pesquisa cientifica e tecnológica", "Estado e pesquisa agrícola no Brasil" e também um capítulo de livro sobre "Estado e modernização: a pesquisa e a extensão na agricultura", coletânea coordenada por minha orientadora, na época uma das referências em sociologia rural no Brasil, intitulado Estado, sociedade e tecnologia agropecuária, a partir de resultados de uma série de pesquisas desenvolvidas desde 1986, com a participação das professoras Ana Maria Fernandes, Maria Stela Grossi Porto, do professor João Gabriel Teixeira. Os artigos apresentavam um pressuposto comum que era o fato de a produção e o uso das tecnologias serem socialmente determinados. Depois fui me afastando aos poucos da tecnologia agropecuária e me voltando mais para a análise da política científica e tecnológica e das condições da pesquisa científica e tecnológica das universidades, ou seja, a associar educação e ciência.

Assim, em 1989 e 1990, publiquei artigos sobre "Universidade e pesquisa na nova Constituição" que apresentam resultados de uma pesquisa que fiz junto com as professoras Maria Lucia Maciel, Ana Maria Fernandes e Maria Francisca Coelho entre outros, durante a Constituinte, e na qual pude acompanhar de perto as comissões de Educação e de Ciência, tecnologia e comunicação. Nessa ocasião, a discussão principal abordava a garantia de recursos públicos para as universidades públicas e também para a pesquisa básica que deveria preservar a sua autonomia. Essa questão também foi abordada em artigo elaborado por mim e pela professora Vilma Figueiredo sobre "A pesquisa nas universidades brasileiras", no qual mostramos, por meio de dados estatísticos, que embora as universidades públicas e algumas católicas (PUCS) se destacassem por sua capacidade instalada e pelos índices de produtividade, a articulação entre a produção universitária e outros setores da sociedade era complexa e ainda tênue. O dilema básico da pesquisa universitária se referia à garantia de autonomia acadêmica e científica na sua formulação e condução e, ao mesmo tempo, à garantia de financiamento para a sua realização. Da solução adequada desse dilema iria depender a articulação dessa produção com as demandas da sociedade, questão que permanece atual.

Minhas pesquisas e publicações sempre abordaram as condições de produção de conhecimento nas quais se incluem a análise das políticas de apoio à pesquisa ou das próprias políticas de C\&T. Nesse sentido, considero hoje que as condições de 
produção de conhecimento devem ser consideradas como condições cognitivas ou intrínsecas ao próprio processo de conhecimento (por exemplo, a acumulação de conhecimento na área, a existência de um paradigma hegemônico ou de teorias em competição) e como condições socioinstitucionais, até certo ponto externas ao processo de conhecimento (por exemplo, certas características do contexto econômico e político, políticas governamentais de apoio ou de restrição à produção, financiamento, criação de instituições), observando que, de fato, essas condições não estão separadas, tanto que em artigos mais recentes já falo de condições sociocognitivas.

Dando continuidade, escrevi artigos nos anos 1990 sobre "A política científica e tecnológica e o projeto de desenvolvimento nacional", fruto do meu pós-doutorado na École des Hautes Études en Sciences Sociales, Paris, como também sobre "As políticas de educação, C\&T na década de 90", no qual apresentei vários programas governamentais e mostrei como se afinavam com as concepções de educação para a competitividade e para a cidadania social. Essa associação entre educação e ciência também está presente em artigo de 2009 sobre "Qualidade acadêmica e relevância social e econômica da educação superior", no qual apontei o grande desafio vivenciado pela universidade: o de atender aos requisitos de qualidade enquanto mérito acadêmico de sua produção e também enquanto relevância econômica e social, dadas as condições sociocognitivas que influenciam a definição dessa qualidade complexa pela política governamental. Para tal, foram analisados documentos relativos à avaliação da graduação e pós-graduação e outros referentes às políticas de ciência, tecnologia e inovação (CT\&I) e relativos aos principais programas e prioridades de fomento à pesquisa, mostrando ainda que essa qualidade complexa é uma preocupação expressa na retórica de líderes de pesquisa em diferentes áreas de conhecimento quando se referem às suas práticas de pesquisa. Aliás, gostaria também de enfatizar que tudo que produzi vem de resultados de pesquisas, nas quais foram analisados documentos, dados estatísticos e entrevistas realizadas, seja com pesquisadores ou com gestores governamentais da área.

No início dos anos 2000, escrevi sobre a política de pós-graduação e sobre a importância das ciências sociais na política e no desenvolvimento da CT\&I. No que concerne à pós-graduação, um dos artigos fez uma recuperação histórica da política de pós-graduação por meio da análise das principais questões colocadas pelos Planos Nacionais de Pós-Graduação, mas também propôs uma discussão sobre os novos rumos, nos quais se incluem a flexibilidade, a diversidade das áreas, a interdisciplinaridade, os mestrados e os doutorados interinstitucionais. Quanto a esse último aspecto, foi com muita satisfação que vi o nosso programa de pós-graduação constituir um programa de doutorado interinstucional com a Universidade de Tocantins, no qual dei aulas de Teorias sociológicas, participei do processo de seleção 
e orientei uma das teses. Embora com muitas dificuldades, é uma das formas pelas quais podem ser reduzidas as desigualdades regionais.

Em outro artigo sobre política de pós-graduação, analisei um conjunto de informações da Coordenação de Aperfeiçoamento de Pessoal de Nível Superior (Capes) sobre a evolução da pós-graduação brasileira no período de 1987 a 2003, mostrando, ao final, a necessidade de se pensar essa política de forma menos homogênea e mais diversificada, visando perfis, ethos e culturas disciplinares diferentes como também temas muiltidisciplinares, respeitando vocações regionais e institucionais. Dessa forma, a pós-graduação poderia contribuir melhor para o desenvolvimento de um "modelo misto de produção científica e tecnológica", conceito elaborado pelo professor Michelangelo Trigueiro e por mim, em artigo de 1994. Esse modelo procura unir a lógica do campo científico, ou seja, as demandas da própria evolução da ciência às demandas econômicas e sociais, reconhecendo, porém, as diferenças entre áreas, com necessidades distintas, umas mais aplicadas ou tecnológicas que outras, ou ainda, umas mais articuladas às demandas das políticas públicas e das organizações não governamentais e outras às demandas do setor produtivo.

No que se refere especificamente à pós-graduação em sociologia, em 2013 publiquei um artigo intitulado "A educação na pós-graduação em sociologia: um objeto esquecido ou escondido?", cujo objetivo foi traçar um panorama da pós-graduação em sociologia, sobretudo no que concerne às suas áreas de concentração e linhas de pesquisa, procurando verificar como o tema da educação estava inserido num espaço de dez anos, ou seja, nos anos de 1999 e 2009, a partir dos indicadores da Capes. Dessa forma, foram apresentados os temas de pesquisa que permaneceram, os temas emergentes e aqueles que desapareceram ou foram remodelados. Os temas predominantes nas linhas de pesquisa da pós-graduação em sociologia, nos dois anos considerados, foram "cultura", "política", "trabalho", "políticas públicas", "violência/conflito/criminologia", "cidades/urbano", "desigualdades/diversidade/ diferenças", "pensamento social". Já as inflexões foram verificadas nos temas referentes à "agricultura, rural e agrário", "religião" e "gênero", que ocupavam nove linhas de pesquisa e, em 2009, passaram a preencher sete, talvez em função de sua inserção na questão das "desigualdades/diversidade/diferenças". No caso da "educação", verificou-se que havia sete linhas de pesquisa em 1999, número já considerado pequeno em relação ao que ocorria com as linhas de pesquisa mais frequentes, mas que ainda diminuíram para três em 2009. Deve-se registrar ainda que os temas associados à demografia, tais como "estudos de população" e "migrações" não apareceram mais nas linhas de pesquisa da sociologia no ano de 2009. Porém, novos temas foram surgindo como "meio ambiente" e "corporeidade". No entanto, o tema da educação parece estar embutido em outras linhas de pesquisa dos cursos 
de pós-graduação em sociologia que não tratam exclusivamente e especificamente de educação. A partir da leitura da descrição das linhas de pesquisa e dos projetos de pesquisa nelas incluídos, também disponíveis nos indicadores da Capes, foi possível descobrir que muitas vezes o tema da "educação" está incluído nos temas concernentes à "cultura", "desigualdades", "conhecimento", "políticas públicas" e "trabalho", alguns deles proeminentes na pós-graduação em sociologia.

Com relação aos desafios das ciências sociais no desenvolvimento científico e tecnológico contemporâneo, mostrei que as ciências sociais têm de se mostrar relevantes, mesmo que não sejam consideradas prioritárias na política de CT\&l, analisada pelos Planos Plurianuais (PPAs), Fundos Setoriais, Estratégias Nacionais de Ciência, Tecnologia e Inovação (ENCTI), Institutos do Milênio e Institutos Nacionais de Ciência e Tecnologia (INCTs). Ou seja, as ciências sociais devem produzir conhecimento reflexivo, refazendo a nossa tradição, que é a de reflexão sobre as instituições e as transformações sociais em curso. A origem da sociologia se deu num contexto social em ebulição, pois surgia uma nova sociedade industrial, moderna, capitalista, na qual os clássicos da sociologia analisaram as classes sociais, a divisão de trabalho e a solidariedade, a emergência do individualismo, a constituição do Estado nacional, a substituição da religião pela ciência, a contribuição da ciência para a acumulação de capital, para a secularização da sociedade e para a reforma moral da sociedade (no caso da sociologia). Mas é importante destacar que a sociedade contemporânea está também em transformação e que as ciências sociais, juntamente com outras disciplinas, têm estudado novas relações de trabaIho, fenômenos culturais, processos educacionais e de produção de conhecimento, formas de violência, questões de gênero e de raça, vários tipos de expressão das desigualdades sociais, impactos sociais da revolução científica e tecnológica. Mas esses temas nem sempre constam dos PPAs, das ENCTI ou dos Fundos Setoriais por mim analisados. Contudo, alguns desses temas tiveram financiamento dos Institutos do Milênio e INCTs e têm dado subsídios para as políticas públicas, como é o caso dos INCTs que trabalham sobre violência e segurança pública e sobre política urbana, dentre outros.

Em suma, tenho explicitado que na política de CT\&I dos últimos dez a quinze anos, há uma preocupação com a interação entre o conhecimento científico e tecnológico e a sociedade, tanto na sua expressão econômica como social. Há novas formas de financiamento nas agências federais e estaduais, com editais mais aplicados e temáticos, além dos editais universais. Porém, foi observada a dificuldade ainda de implementação efetiva da interdisciplinaridade por meio dos Fundos Setoriais. Muitos deles continuaram concentrados em determinadas áreas de conhecimento, com reduzida participação das ciências humanas. Ou seja, o modelo de fomento nem 
sempre considera a diversidade das áreas de conhecimento, além da concentração em determinadas regiões e instituições, e da participação insuficiente do setor produtivo e das organizações não governamentais (ONGs). Porém, tomando a concepção de Bourdieu de campo científico que rompe com a dicotomia entre ciência pura (livre das necessidades sociais) e ciência escrava ou aplicada (dependente das necessidades econômicas, políticas e sociais), ele mostra a existência de um universo intermediário que é o campo científico, um mundo social como os outros, mas que possui leis próprias de funcionamento, ainda que retraduza demandas externas. Pode-se então construir o logos, não simplesmente traduzindo, mas retraduzindo o socius. Essa é uma das formas de inserção das ciências sociais nos novos caminhos da política de CT\&I. Mas cabe também às ciências sociais lutar para que os temas sociais sejam prioritários na agenda governamental de apoio à pesquisa e, ao mesmo tempo, analisar, junto com outras disciplinas, o conteúdo social de certos campos aparentemente não sociais. Cito alguns exemplos: como pensar uma política de biocombustível para o Brasil sem considerar a questão da propriedade agrícola? Como o setor produtivo pode inovar em determinados produtos sem considerar aspectos culturais?

Também no início dos anos 2000, trabalhei sobre as condições de constituição de certos campos científicos como foi o caso da economia e da física. Verifiquei que a física se constituiu como campo científico pela pesquisa, com o apoio do CNPq, e depois da política de pós-graduação da Capes; já em relação à economia o caminho foi diferente, atraiu importância com a política de pós-graduação, além da Fundação Ford e da figura de Werner Baer da Universidade de Illinois, para a qual vários economistas brasileiros foram realizar o seu doutoramento. Mostrei também que embora a economia tenha nascido com a contabilidade e depois tenha se associado às ciências sociais, a tendência hegemônica naquele momento era de querer se tornar uma ciência exata, com a utilização de modelos matemáticos. Nesse período, embora trabalhasse principalmente com as ideias de campo científico de Bourdieu e do poder do conhecimento de Foucault, descobri a importância de certos líderes que criam, consolidam ou transformam instituições, como foi o caso na economia de Maria da Conceição Tavares com a Universidade Estadual de Campinas (Unicamp) e Universidade Federal do Rio de Janeiro (UFRJ), de Delfim Neto com a Universidade de São Paulo (USP) e de Mario Henrique Simonsen na Fundação Getúlio Vargas (FGV). Na Física, destacaram-se líderes como Sérgio Mascarenhas na USP e Sérgio Rezende na Universidade Federal de Pernambuco (UFPE), entre outros. Ou seja, além da evolução do conhecimento e das políticas de apoio já por mim analisadas, certos atores tiveram uma importância fundamental na construção de instituições e na produção de conhecimento. Daí surgiu a ideia da pesquisa sobre "lideranças científicas" nas engenharias, na genética e na sociologia. As diferenças 
entre os perfis das grandes áreas de conhecimento e a importância das lideranças científicas, apontadas em pesquisas anteriores, levaram-me a analisar as principais práticas dessas lideranças na produção do conhecimento e na definição da política científica e tecnológica. Foram observadas que as condições sociocognitivas definidas pela estrutura e pelos atores do campo, de diferentes maneiras, delineavam as práticas de produção do conhecimento científico e tecnológico e, ao mesmo tempo, apontavam as principais características das áreas de agronomia, genética e sociologia. Por outro lado, foi indicado também, como tendência, um "modelo misto de produção científica e tecnológica", no qual estão associadas a pesquisa básica à aplicada e à inovação tecnológica, a demanda espontânea à induzida, a comunidade científica a outros atores sociais como o governo, as organizações não governamentais e o setor produtivo. Minha análise permitiu afirmar que os pesquisadores estavam construindo caminhos de atualização, sem perder totalmente as suas tradições. Desenvolviam a sua vocação cosmopolita e científica, a fim de contribuir para a evolução do conhecimento, procurando, ao mesmo tempo, solucionar determinados problemas econômicos e sociais, alguns de caráter regional, e interagir com outras instituições e outras disciplinas. Embora não estivessem necessariamente respondendo a demandas específicas, o que pode indicar uma produção "ofertista" - segundo Renato Dagnino -, estavam começando a interagir com outras instituições, além daquelas de ensino superior e também com outras disciplinas afins ao seu objeto de estudo, procurando, ao mesmo tempo, contribuir para solucionar determinados problemas econômicos e sociais, alguns de caráter regional. Afirmei então que o campo da ciência, tecnologia e inovação era híbrido, ou seja, ao mesmo tempo excelente e real, na medida em que a lógica da ciência continua avançando e que o processo de globalização e a democratização da sociedade passam a exigir, cada vez mais, uma C\&T comprometida com a economia e com a responsabilidade social.

Gostaria também de mencionar as dez dissertações de mestrado e vinte teses de doutorado que orientei. Nessas orientações, também procurei associar temas educacionais aos temas relacionados à CT\&I. Os temas educacionais que orientei foram vários: as propostas educacionais do Partido dos Trabalhadores (PT), as representações sociais dos alunos da rede pública do Distrito Federal sobre a sociologia no ensino médio, as representações sociais sobre cidadania e espaço público a partir da escola de ensino médio, a constituição da Universidade Federal do Piauí (UFPI), a modernização reflexiva e a avaliação no contexto das transformações do ensino superior, os desafios do ensino técnico profissionalizante, o trabalho docente nas instituições de ensino superior privadas, as profissões agrárias, estas últimas na fronteira entre sociologia da educação e do trabalho. Entre os temas de educação e CT\&l, podem ser citados a formação científica e tecnológica no novo modo de 
produção de conhecimento, a educação a distância e as novas tecnologias da informação e comunicação, as políticas de formação em saúde no Brasil e na Argentina, as políticas de mobilidade internacional de pós-graduandos e a internacionalização do conhecimento. Sobre as políticas de CT\&I, orientei algumas teses sobre os confrontes e os contrastes do desenvolvimento científico e tecnológico brasileiro que trata das desigualdades regionais, os Fundos Setoriais, os programas públicos de inclusão digital, os organismos internacionais para apoio à C\&T. No que se refere à produção de conhecimento, os temas orientados foram a autonomia reflexiva e a produção do conhecimento na sociologia, a produção de conhecimento sobre meio ambiente nas universidades e a produção de conhecimento no âmbito dos Fundos Setoriais. Também orientei sobre a estrutura das chaves públicas e a formação do Estado eletrônico, na qual se mostra a contribuição da ciência e da tecnologia para a política e até outros temas mais distantes da minha área de pesquisa propriamente dita, como aqueles concernentes às políticas de saúde, à política sanitária para os organismos geneticamente modificados (OGMs), à cidadania nas relações afetivo-sexuais, às elites parlamentares e à questão social no Brasil e Uruguai, mas nos quais sempre foi ressaltado o papel da C\&T. Atualmente, estou orientando uma tese sobre uma política educacional de formação de docentes, ou seja, sobre o Programa Institucional de Bolsa de Iniciação à Docência (Pibid) nas ciências sociais. Finalmente, cabe registrar que esses trabalhos resultaram numa série de livros e artigos publicados.

Devo observar que muitos dos conceitos ou das ideias construídos ao longo de minha trajetória - como o de condições sociocognitivas e o de modelo misto de desenvolvimento científico e tecnológico (junto com Michelangelo Trigueiro) - foram aprimorados por algumas dessas teses e dissertações. O trabalho de orientação, ainda que seja oneroso, não deixa de ser prazeroso, pois nesse processo se ensina, mas também se aprende muito, não apenas em termos de conteúdo, mas também nas formas de relacionamento com as pessoas. Além do fato de ser muito gratificante ver o crescimento dos orientandos. Nesse sentido, outro destaque a ser feito é que, nas minhas pesquisas, sempre contei com a participação de alunos do Programa Institucional de Bolsa de Iniciação Científica (Pibic), que, muitas vezes, começavam a trabalhar na pesquisa sem entender muito do assunto, mas, que, com o tempo, a partir das leituras indicadas e da pesquisa empírica, já me davam sugestões pertinentes.

Embora tenha me aposentado em 2005, nunca me considerei inativa. Continuei pesquisando, produzindo, orientando e até lecionando na pós-graduação, ainda que sem a mesma regularidade de antes. Também atuei como pesquisadora visitante no Centro de Gestão e Estudos Estratégicos (CGEE) durante quatro anos, onde 
tive uma experiência muito rica em avaliação e planejamento estratégico de CT\&I. No que concerne à avaliação, foi muito interessante verificar resultados e impactos esperados e inesperados de determinadas políticas, tais como os das Olimpíadas Brasileiras de Matemática na Escola Pública (Obmep), com a participação dos ex-orientandos Gilberto Lacerda Santos e Tatiana Maranhão e do programa INCTs, no qual pude observar resultados de pesquisas realizadas e seu aproveitamento tanto pelo setor produtivo como pelo setor governamental. Ou seja, continuei analisando as políticas, porém agora mais próxima talvez de sua aplicação. Quanto ao Programa Ciência sem Fronteiras, foi feita uma proposta metodológica (sob a coordenação da professora Lea Velho, da Unicamp) para se avaliar os seus primeiros resultados, mas que não foi concretizada. Também nesse período, ainda no CGEE, fui coordenadora da elaboração do planejamento estratégico para o CNPq com a participação dos funcionários da casa e de cerca de 100 membros da comunidade científica. Por um lado, foi enriquecedor pensar coletivamente o futuro de uma agência de fomento, mas, por outro, poucos pontos levantados foram incorporados na prática. Ou seja, se condicionantes cognitivos e socioinstitucionais permitiram a produção de conhecimento avaliativo sobre um programa de formação de recursos humanos e um planejamento estratégico de uma agência de fomento, outras condições não permitiram a continuidade da avaliação e a incorporação da maioria dos resultados desse conhecimento nas ações das agências de fomento. A produção e a apropriação social do conhecimento continuaram sendo a tônica do meu percurso, ainda que com novos ingredientes e sob novas formas.

Nos últimos anos, ainda que dando continuidade às análises sobre a produção do conhecimento e sobre a política científica e tecnológica, tenho atuado mais diretamente, talvez como militante da área de CT\&I, no âmbito de diversas sociedades científicas, como a Associação Nacional de Pós-Graduação em Ciências Sociais (Anpocs), a Associação Brasileira de Estudos Sociais em Ciências e Tecnologias (Esocite), a Sociedade Brasileira de Sociologia (SBS) e a Sociedade Brasileira para o Progresso da Ciência (SBPC). Além de escrever sobre a importância das ciências sociais no desenvolvimento científico e tecnológico, tenho participado de vários conselhos e comissões com esse objetivo, como foi o caso no Grupo de Trabalho constituído pelo Fórum de Ciências Humanas, Sociais e Sociais Aplicadas para justamente traçar uma política científica das ciências humanas, sociais e sociais aplicadas (CHSSA) para o CNPq e enquanto representante da SBS no Grupo de Trabalho de Ciências Humanas e Sociais na Comissão Nacional de Ética em Pesquisa (Conep), que, finalmente, depois de muitos conflitos, conseguiu aprovar uma regulamentação específica sobre ética na pesquisa para a nossa área dentro do Conep. Porém, ainda que seja um avanço essa regulamentação específica, considero que a ética na pesquisa deve ser regulamentada pelo MCT\&I e não pelo Conselho Nacional de Saúde. 
No âmbito da SBPC, como conselheira, tenho tido uma convivência rica com outras áreas de conhecimento que tem me permitido dialogar e entender necessidades das nossas pesquisas e também de outros campos científicos, como também as principais contribuições, o que permite ultrapassar o discurso da vitimização e mostrar a importância das CHSSA para o desenvolvimento científico e tecnológico do país, como aconteceu recentemente, ao participar da discussão da elaboração da nova ENCTI, na qual pouco se fazia referência a temas afins a nossas disciplinas e que consegui apontar alguns deles. Finalmente, também espero que o conhecimento da área de CT\&l e a compreensão das diferenças entre as áreas de conhecimento me permitam trabalhar melhor nas condições institucionais do apoio à pesquisa no âmbito do Decanato de Pesquisa e Pós-Graduação, onde estou atualmente como Diretora de Pesquisa, pois educação, ciência e tecnologia fizeram a minha trajetória junto com muitos de vocês que estão aqui presentes e de outros que estão ausentes e a quem muito agradeço. 